\title{
Abordagens Teóricas para Estudos Sobre Cultura Pop
}

Thiago Soares

Professor do Programa de Pós-Graduação em Comunicação (PPGC) da Universidade Federal de Pernambuco e do Programa de Pós-Graduação em Comunicação e Culturas Midiáticas da Universidade Federal da Paraíba (UFPB) e pesquisador do Laboratório de Análise de Música e Audiovisual (LAMA) na UFPE.

Resumo: $\mathrm{O}$ artigo apresenta balizas teóricas para o estudo de produtos midiáticos da cultura pop. Envolve definiçóes acerca do pop, das lógicas de produção e consumo e reivindica um olhar para além das premissas apocalípticas dos autores da Escola de Frankfurt em torno de estéticas ancoradas em sistemas industriais do capitalismo tardio. A premissa é reconhecer o estudo da cultura pop como ancorado na interface com a Teoria Crítica, os Estudos Culturais e a Economia Política da Comunicação. Dessa forma, postula-se que as linguagens dos produtos da cultura pop encenam formas particulares de fruiçáo e engajamento, legando aos sujeitos uma vivência estética fortemente pautada pela noçáo de performance.

Palavra-chave: Cultura Pop; Entretenimento; Mídia

Abstract: TThe article presents theorical perspectives to study pop culture's products. Starts with definitions about pop, production and consumption and points an overview that suggests to get far from the apocalyptical ensembles from authors of School of Frankfurt. Defends that late capitalism has aesthetical implication in products and recognizes pop culture anchored in between Critical Theory, Cultural Studies and Political and Economical Studies in Media. Somehow, languages of pop culture products acts and suggests different ways of affections and experiences, envolving subjects in an aesthetical every day life strongly influenced by performance

Keywords: Pop Culture; Entretainment, Media 
Não é de hoje que se usa com freqüência o termo pop para classificar produtos, fenômenos, artistas, lógicas e processos midiáticos. De maneira mais ampla, a ideia de pop sempre esteve atrelada a formas de produção e consumo de produtos orientados por uma lógica de mercado, expondo as entranhas das indústrias da cultura e legando disposiçóes miméticas, estilos de vida, compondo um quadro transnacional de imagens, sons e sujeitos atravessados por um "semblante pop" (GOODWIN, 1992). O termo pop tornou-se elástico, amplo, devedor de um detimento em torno de suas particularidades e usos por parte de pesquisadores das Ciências Humanas. É na direção de um enfrentamento conceitual e na tentativa de demarcar balizas de diálogos com matrizes teóricas já consagradas no campo da Comunicação que este artigo se delineia. Parte das questôes que aqui aponto foram frutos da palestra "Cultura Pop: Abordagens Possíveis", que proferi em outubro de 2011, no Programa de Pós-Graduação em Comunicação da Universidade do Vale do Rio dos Sinos (Unisinos), em Sáo Leopoldo, no Rio Grande do Sul, a convite dos professores Adriana Amaral e Fabrício Silveira (2).

Um preâmbulo: acho importante pontuar que algumas nuances experienciais que trago, ao longo do texto, se deram em função da minha fruição de produtos da cultura pop, notadamente artistas musicais como Madonna, Britney Spears, Rihanna, Miley Cyrus, Lady Gaga, entre outros. Acho importante demarcar este ponto de partida porque tratar a cultura pop como um conjunto de práticas de consumo sugere pensar uma espécie de vivência pop no cotidiano. Porque estar imerso na cultura pop é se estender por objetos que falam por clichês, por frases de efeito, por arranjos musicais já excessivamente difundidos, por filmes cujos finais já sabemos, cançôes cujos versos já ouvimos, refróes que nos arrepiam, cenas de novela que nos fazem chorar, e por aí adiante. O que parece "vazar" naquilo que o bom gosto, a "norma culta", o valorativo, a "intelectualidade" soam atestar como excessivamente comercial, deliberadamente afetivo e ultra-permissivo, nos interessa. E nos interessa porque, de alguma forma, nos habita.

Este texto se ancora em torno de afetos em torno de objetos que não trazem retrancas claras de valor estético. Também me parece uma questão a ser debatida no bojo do que mapeio aqui como abordagens possíveis da cultura pop justamente este tipo de produção cultural. Antes de tudo, acho fundamental fazer algum tipo de esboço conceitual do que chamo cultura pop. De maneira mais detida, significa enfrentar teórica e empiricamente um termo excessivamente usado no jornalismo cultural, no universo do entretenimento, no senso comum. Atribuímos cultura pop, ao conjunto de práticas, experiências e produtos norteados pela lógica midiática, que tem como gênese o entretenimento; se ancora, em grande parte, a partir de modos de produção ligados às indústrias da cultura (música, cinema, televisão, editorial, entre outras) e estabelece formas de fruição e consumo que permeiam um certo senso de comunidade, pertencimento ou compartilhamento de afinidades que situam indivíduos dentro de um sentido transnacional e globalizante. Quero inclinar algumas perspectivas apontadas nesta definição que, talvez, ajudem a reconhecer o papel da cultura pop no debate no campo da Comunicação - sem um 
certo ranço das abordagens frankfurtianas.

A primeira tônica da definição de cultura pop diz respeito a práticas, experiências e produtos norteados pela lógica midiática. Chamo lógica midiática a premissa de que estamos atravessados por territórios informacionais (LEMOS, 2008), que habitamos duplamente espaços - reais e virtuais -, que talvez não seja possível falar tão aberta e acintosamente em "real" e "virtual", uma vez que ambos estão imbricados, perpassados, unidos de forma a que o cotidiano passa a ser um duplo em que fazemos açóes e (mais uma vez) fazemos açôes: açôes "reais", açôes "virtuais" - que se agenciam, se interpenetram, agem uma em função da outra, modos de experienciar o presente a partir de camadas de sentido que estáo ligadas a formas de relacionamento com os meios de comunicaçáo. Estamos numa era da performance, da alteridade, do eu "real" e do eu "virtual" cada vez mais imbricados, indissociáveis. Pensar a natureza dessas performances é uma das chaves de entendimento dos entornos sobre uma vivência pop.

Destaco que, ao falar de produtos da cultura pop, retiro de cena, na apropriação conceitual que aqui aponto, parte do debate do produto midiático que se filia, por exemplo, a uma tradição da crítica da estética da mercadoria (HAUG, 1997), que aponta a tal estética da mercadoria como um modo, digamos, nocivo de experienciar os objetos que estariam excessivamente codificados pelas relaçóes mercantis e capitalistas. É neste ponto que, talvez, resida o ponto nevrálgico do debate conceitual sobre cultura pop: reconhecemos um lugar da experiência e das práticas dos indivíduos que sáo permeadas por produtos, gerados dentro de padrôes normativos das indústrias da cultura, que se traduzem em modos de operaçôes estéticas profundamente enraizados nas lógicas do capitalismo, mas que encenam um certo lugar de estar no mundo que tenta conviver e acomodar as premissas e imposiçôes mercantis nestes produtos com uma necessidade de reconhecimento da legitimidade de experiências que existem à revelia das consignações do chamado capitalismo tardio.

Em outras palavras, quero lançar luz ao fato de que, embora seja claro e evidente que os produtos e as formas culturais em circulação na cultura pop estejam profundamente enraizados pela configuração mercantil, pelas imposiçôes do capital (de modo de produção, formas de distribuição e consumo), não se invalidam abordagens sobre a pesquisa neste segmento da cultura que reconhece noções como inovação, criatividade, reapropriação, entre outras, dentro do espectro destes produtos midiáticos. Menciono, portanto, a ideia de que estamos num estágio do capitalismo em que não podemos trabalhar análises binárias sobre as relaçóes entre capital e cultura. Os produtos culturais, hoje, têm em sua gênese, a ingerência de um sentido do capital, aquele atrelado ao marketing e às formas de posicionamento de marcas dentro de uma cultura. Empresas dos mais diversos segmentos apóiam, muitas vezes através de insenção fiscal, a realização de filmes, a edição de álbuns fonográficos, de livros, entre outros. Eventos ligados à cultura pop, os festivais de música, de cinema, as feiras literárias, entre inúmeros outros, também contam com apoios governamentais (seja de ordem municipal, estadual ou federal), mas são, sobretudo, 
as marcas que gerenciam, apontam e se ancoram na realização de eventos que são, em si, uma forma de experienciar tanto a cultura quanto um certo sentido imbuído pelas empresas.

Estou aqui destacando que a relação entre marcas e produtos culturais precisa ser pensada não somente a partir de retrancas estanques (como o produto é "distorcido" pela ingerência do marketing na sua gênese, por exemplo), mas diante de um quadro em que se leve em consideraçáo que as açôes de organizaçóes, de marcas, de posicionamentos de empresas, se aproximam das expressôes da cultura de forma a gerar produtos/processos que não são, necessariamente, tolhidos de qualquer verve de criatividade e inovação. A questão, aqui, não é obliterar as experiências em que, de fato, a ingerência de disposiçóes mercantis age de forma a reestruturar propostas estéticas, por exemplo. Mas, reconhecer brechas na lógica de produção das indústrias da cultura e na cibercultura que permitam o questionamento de ordem estética e cultural destes produtos.

\section{Cultura e "mundo das marcas": tensóes}

O enquadramento conceitual que proponho aqui tenta colocar em destaque a noção de cultura em consonância com a de marketing: ambos já estão enraizados de forma a que não podemos mais fazer análises de produtos da cultura midiática sem discutir, por exemplo, esta engrenagem de marketing e de posicionamentos de produtos que fazem com que, inclusive, tais produtos midiáticos cheguem até os contextos de fruição. Justapor, portanto, cultura e marketing não significa colocá-los em diálogo. Pelo contrário. O interessante é, exatamente, perceber os atritos, as tensôes, as lógicas de produção que estão em jogo nas relações entre a produção cultural e o marketing. É possível que se questione uma valoração excessiva que estou dando para o marketing, a ponto de colocá-lo como "análogo" à noção de cultura. E, então, quero me deter sobre esta perspectiva. Minha aproximação entre os dois se dá porque considero, ambos, como espaços de disputa e tensão, construídos a partir de linguagens e de experiências contextuais e acionados a partir de disposiçôes simbólicas.

Considerar o marketing como um espaço prevê reconhecer aquilo que Mickey (1997) chama de "Logo World" ou "o mundo das marcas", na verdade, trata-se de um ponto de partida em que a nossa relação com os objetos do mundo passa a ser a nossa relação com as marcas. Aliás, o mundo é encarado como codificado a partir de marcas. Se pensarmos numa certa economia das trocas simbólicas (BOURDIEU, 1974), estaríamos diante de um quadro em que os dispositivos simbólicos dos produtos são as marcas. Física (produto) e metafísica (marca) em espaços de atrito e tensão. Esta relação se daria não somente diante de bens duráveis, em que estaria clara a associação entre matéria e disposição simbólica, mas também diante de bens intangíveis. Marcas se apropriando de espaços públicos, de festividades populares, de formas de ser e estar no mundo. A nossa preocupação aqui não se dá diante da ideia utópica de que "seria melhor se não fosse assim", pressupondo entender que havia uma cultura, digamos, mais "pura" quando esta estava menos enraizada com o marketing avassalador da contemporaneidade. Se pensarmos que a cultura é, 
em si, um ambiente de disputas e tensões, precisamos nos lembrar que historicamente, a produção cultural sempre esteve atrelada a interesses, a formas de viabilização que pressupunham práticas que visavam retornos econômicos e, também, a normatizaçôes distintivas nestes contextos.

Obviamente que os discursos do marketing, hoje em dia, se encontram ancorados em produtos e expressóes culturais de forma a que tais manifestações consigam visibilidade, notoriedade e distinção dentro de um quadro de uma sociedade atravessada pelas encruzilhadas da midiatização. Portanto, pensar a cultura como este espaço de disputas entre instituiçôes e expressões culturais, seus produtos e processos e as dinâmicas do marketing e das imposiçôes do capital não deve ser uma retranca que reivindique uma "pureza" ou uma "deformação" das questốes da cultura em detrimento ao marketing, mas entender qual o jogo de forças que se delineia, como as configuraçôes se acionam e, também, que lugares nas dinâmicas de inovação e criatividade ocupam os sujeitos imersos nestes processos.

\section{Entretenimento e indústrias da cultura}

A discussão em torno da cultura pop se ancora, sobretudo, diante da retranca do entretenimento. Ao que me parece, a noção de pop está intriscecamente ligada às ideias de lazer e de diversão. Quero, aqui, acrescentar mais um dispositivo para pensar o já problemático termo pop: a premissa de que, acionar o pop significa reconhecer o contexto do entretenimento e dos agenciamentos das indústria da cultura em análises e perspectivas. Antes, no entanto, é preciso reconhecer que o termo pop já é, em si, bastante problemático. Primeiro, em função de seu caráter transnacional. Oriundo de língua inglesa como abreviação do "popular", a denominação pop assume uma característica bastante específica em sua língua de origem. Como abreviação de "popular" (pop), a palavra circunscreve de maneira um tanto quanto clara, as expressóes aos quais, de alguma forma, nomeia: são produtos populares, no sentido de orientados para o que podemos chamar vagamente de massa, "grande público", e que são produzidos dentro de premissas das indústrias da cultura (televisão, cinema, música, etc). Seria o que, no Brasil, costuma-se chamar de "popular midiático" ou "popular massivo". A título de exemplo, estamos falando de telenovelas, filmes produzidos dentro dos padróes de estúdio, artistas musicais ligados a um ideário de indústria da música, entre outros.

Esta denominação tão específica do termo na língua inglesa também se avilta em função da abreviação do "popular" em pop fazer referência ao movimento artístico da Pop Art, aquele surgido no final da década de 1950 no Reino Unido e nos Estados Unidos, que propunha a admissão da crise da arte que assolava o século XX e a demonstração destes impasses nas artes com obras que refletissem a massificação da cultura popular capitalista (3). Estávamos diante de um momento histórico em que a discussão implantada era a da existência de uma estética das massas, tentando achar a definição do que seria a Cultura Pop, mas, neste momento, aproximando-a do que se costuma chamar de "kitsch". Temos, então, no contexto da língua inglesa, o pop como o "popular midiático" em consonância com os ecos das premissas conceituais da Pop 
Art. Estas aproximaçôes norteiam o uso do pop e também fazem pensar que a principal característica de todas as expressóes é, deliberadamente, se voltar para a noção de retorno financeiro e imposiçóes capitalistas em seus modos de produção e consumo.

Estas acepções se diferenciam quando chegamos ao contexto da língua portuguesa, em que também se usa a expressão pop, aqui também se referindo à mesma ideia de "popular midiático" original, no entanto, ao nos referirmos ao conceito de "popular", temos uma ampliação do espectro de atuação das noçôes semânticas: o "popular”, na língua portuguesa, pode se referir tanto ao "popular midiático" ao que nos referirmos anteriormente, mas também - e de maneira mais clara e detida - ao "popular" como aquele ligado à "cultura popular" (ou folclórica) e que na língua inglesa não se chama de "popular”, mas sim de folk. Então, ao mencionarmos a ideia de "cultura popular", em língua portuguesa, estamos nos referindo a duas expressóes: a da cultura folclórica, mas também, aquela que chamamos de "cultura pop" ou a "cultura popular midiática/massiva”.

Uma vez debatidos os ecos conceituais da noção de pop, é preciso se ater ao que chamamos de entretenimento. A despeito de uma larga acepção do entretenimento ligado ao jogo, à brincadeira, ao lazer, é preciso reconhecer a perspectiva do entretenimento dentro dos estudos de Comunicação. A etimologia da noção de "entretenimento" é de origem latina e vem de "inter" (entre) e "tenere" (ter). A maioria dos sentidos que estão associadas à palavra tangencia a idéia de "iludir" ou "enganar" (HERSCHMANN; KISCHINHEVSKY, 2007, p.1). Segundo Jeder Janotti (2009, p. 3), na definição etimológica já se pode vislumbrar a manifestação de aspectos positivos e negativos que envolvem a ideia de entretenimento. É como se diante de um truque, o "espectador crítico" se sentisse envolvido pela engenhosidade do "número de magia" e ao mesmo tempo a descartasse como um mero "truque", uma simples "ilusão" destinada aos ingênuos. A questáo soa curiosa, mas reflete um dos desafios do tratamento do que chamamos de "produtos do entretenimento", até porque é necessário materializar questóes analíticas do entretenimento em produtos. Por isso, precisamos

preconhecer que, tendo em vista a amplitude do que pode ser abarcado como 'produtos de entretenimento', restringiremos a ideia à produção e fruição de produtos de entretenimento ligados às indústrias culturais, e toda configuração da cultura popular massiva estabelecida ao longo do século XX e início do século XXI. (JANOTTI, 2009, p. 2)

Uma das orientaçóes metodológica que trazemos à tona é a de que como qualquer expressão midiática, os produtos de entretenimento devem ser analisados a partir das proposiçóes/funçóes prescritas em seus programas de produção de sentido.

Mas isso, não deve obliterar o fato de que entreter-se também significa algo mais, não se pode confundir a presença massiva, e por que não, muitas vezes maçante, da música no cotidiano com a capacidade que certas peças musicais do mundo pop têm de possibilitar fruiçóes estéticas. (JANOTTI, 2009, p. 5) 
O que parece estar em jogo é o que Itânia Gomes (2008) aponta com o fato de que o prazer, a corporalidade, a fantasia, o afeto e o desejo cooperam para o entendimento de que a relaçáo entre a mída e seus consumidores náo se restringe a um problema de interpretação de uma mensagem, mas remete também a questôes de percepção e sensibilidade e nos convoca igualmente à avaliação empírica das sugestões de pensamento de Walter Benjamin, de que as formas comunicativas criam novos modos de ver e compreender o mundo. Nas palavras da autora: "uma nova sensibilidade, um novo raciocínio, mais estético, mais visual e sonoro, que implicam uma nova forma de percepção do mundo, característica da era audiovisual, ainda pouco compreendida”. (GOMES, 2008, p.110)

\section{O pop como senso de pertencimento global}

A cultura pop estabelece formas de fruição e consumo que permeiam um certo senso de comunidade, pertencimento ou compartilhamento de afinidades que situam indivíduos dentro de um sentido transnacional e globalizante. Primeiramente, é importante definir que, inspirados nas abordagens dos Estudos Culturais, considera-se os fruidores/consumidores da cultura pop não só como agentes produtores de cultura, mas também como intérpretes desta. A questáo do sujeito dentro do contexto pop aponta para a definiçáo de que o público interpreta, negocia, se apropria de artefatos e textos culturais, compreendendo-os dentro da sua experiência de vida. A questão que se descortina é a de que produtos da cultura pop ajudam a articular normas de diferenciação dentro dos contextos contemporâneos. Distinçôes de raça, gênero, faixa etária, entre outros, acabam sendo forjados em função das premissas do capitalismo industrial.

Esta linha de raciocínio nos encaminha para o debate em torno do que Douglas Kellner (2001) chama de "cultura da mídia". O autor parece chamar atenção para os interesses e jogos de posicionamento e poder que fazem com que produtos midiáticos habitem a chamada "cultura da mídia" e como os discursos que unem objetos, disposiçóes midiáticas e contextos se engendram. Para Douglas Kellner,

há uma cultura veiculada pela mídia cujas imagens, sons e espetáculos ajudam a urdir o tecido da vida cotidiana, dominando o tempo de lazer, modelando opinióes políticas e comportamentos sociais, e fornecendo o material com que as pessoas forjam sua identidade. O rádio, a televisão, o cinema e os outros produtos da indústria cultural fornecem os modelos daquilo que significa ser homem ou mulher, bem-sucedido ou fracassado, poderoso ou impotente. (KELLNER, 2001, p. 9)

Cabe aqui uma reflexão sobre a classificação de Kellner sobre "cultura da mídia”. Chamo atenção para uma espécie de invólucro simbólico de modelização do cotidiano a partir destes produtos. É de nosso interesse debater a construção da noçáo de que um produto midiático segue relevante dentro de um determinado contexto em função da permanência de seus usos e construtos de atribuição de sentido. Em outras palavras, é no terreno da cultura, do consenso e das lógicas de apropriação que reconhecemos a longevidade de um objeto da cultura midiática. O conceito de Kellner nos ajuda a perceber como produtos 
midiáticos se fazem presentes no tecido da vida cotidiana.

Os videoclipes seriam um ponto para o que podemos chamar de estilo de vida vinculado a uma lógica pop, entendendo o pop como uma premissa notadamente midiática. Como forma de posicionamento de um artista no mercado da música, logicamente, o videoclipe se impóe como uma extensão de um tempo de lazer do indivíduo e modela, com isso, apontamentos e pontos de vista dentro de uma vivência na cultura pop. $\mathrm{O}$ videoclipe fornece material simbólico para que indivíduos forjem identidades e modelem comportamentos sociais extensivos aos propostos pelas instâncias da indústria musical. Os clipes seriam, portanto, desde a sua gênese, nos anos 80 , um dos instrumentais de ensinamento de uma vivência pop, revelando uma maneira particular de encarar a vida a partir da relação deliberada entre a vida real e os produtos midiáticos. Videoclipes, com suas narrativas e imagens disseminadas, fornecem símbolos, mitos e recursos que ajudam a construir uma cultura comum para a maioria dos indivíduos em muitas regiōes do mundo, de forma transnacional e globalizante. "A cultura da mídia almeja a grande audiência, por isso, deve ser eco de assuntos e preocupaçóes atuais, sendo extremamente tópica e apresentando dados da vida social contemporânea." (KELLNER, 2001, p. 9)

Esta questão do videoclipe acionar um senso de pertencimento transnacional se alinha à própria perspectiva que as indústrias da cultura operam: a de que há uma espécie de grande comunidade global que, a despeito dos aspectos locais e da valorização de questóes regionais, aponta para normas distintivas e de valores que estão articuladas a idéias ligadas ao cosmopolitismo, à urbanização, à cultura noturna. É nesta direção que vamos descortinando o fascínio que a cultura pop nos lega diante de espaços, cidades e contextos que parecem, de alguma forma, traduzir este senso: percebamos o quando a cidade de Nova York aciona um imaginário permeado pelo pop. Seja em espaços excessivamente fotografados e documentados como a Times Square, num certo senso de estar no "centro do mundo" ao transitar pela Broadway, com todas as peças musicais em cartaz ou mesmo de estar em locais que já foram excessivamente filmados e exibidos nos cinemas ou na televisão, circular por aqueles espaços parece nos legar a premissa de que, de alguma forma, somos "cidadãos do mundo", pertencemos, vivemos de forma comum atrelados a outros sujeitos também situados em outras partes do mundo. Esta, digamos, vivência pop, no entanto, é ainda mais interessante do ponto de vista teórico e conceitual se pensada nas tensóes e atritos com os contextos de origem dos sujeitos. Em outras palavras, é preciso pensar e investigar onde se encontram os vestígios, os traços, os indícios das relaçôes existentes entre a cultura local e um desejo, uma ânsia pop e cosmopolista e de que forma estas tensóes originam materialidades interpretativas.

O imaginário das cidades pop (mencionei Nova York, mas também podemos pensar em Londres, Paris, Los Angeles, Rio de Janeiro, entre outras) parece nos convocar para uma certa territorialidade comum, uma espécie de lugar que gostaríamos de estar em tensão com o local em que, verdadeiramente, estamos, que vemos em filmes, seriados, programas de TV, etc. Desta 
geografia real e difundida midiaticamente também nasce o anseio por lugares que, de fato, não existem, mas são simulacros deste desejo de pertencimento. De alguma forma, estou me referindo ao que Marc Augé (1994) chamou de não-lugares (aeroportos, parques de diversão, parques temáticos, etc), ambientes criados para não trazerem traços, digamos, locais, para traduzirem o senso de que estamos neste espaço transnacional, contínuo em que podemos codificar e decodificar sem atritos de cognição em função de uma certa "marca local”. É do encontro entre esta noção de pertencimento global e cosmopolita, com as marcas específicas locais e ainda diante das próprias filigranas dos indivíduos que emergem esta sensibilidade pop a que me refiro; sensibilidade esta que parece conectar indivíduos do mundo inteiro seja sob a retranca daqueles que se fantasiam de personagens de histórias em quadrinho ou de cinema, os cosplays; ou mesmo em função da cultura dos fẫs, da ideia de uma comunidade específica que pode ignorar territorialidades, marcas das línguas diferentes, mas existe diante de uma marca simbólica ancorada no midiático.

\section{Filiações conceituais sobre cultura pop}

Quero finalizar esta breve síntese de abordagens possíveis na ampla retranca da cultura pop apontando alguns autores, correntes e estudos que nos ajudam a balizar as perspectivas aqui delineadas. Primeiramente, sinto necessidade de lembrar aqui alguns estudos extremamente importantes, dentro da tradição dos Estudos Culturais, que apontaram para questóes ligadas, por exemplo, a fenômenos próximos à Cultura Pop: a questão dos valores da música, notadamente o rock, na obra de Simon Frith (1996); abordagens sobre economia de mercado, indústrias fonográficas e "embalagens"/endereçamentos de produtos musicais nas análises de Andrew Goodwin (1992); o debate em torno de programas televisivos "enlatados" e excessivamente codificados nos textos de John Fiske (1989, 1995); a questão do cinema comercial norte-americano, as formas "fáceis" das indústrias culturais e os impasses ideológicos gerados nestes embates por Douglas Kellner (2001), entre outros. Tais abordagens, evocadas sobretudo em função de uma deliberada permissividade que os Estudos Culturais legaram, encontram novos impasses na contemporaneidade. Sinto necessidade, na tradição culturológica, de colocar em relevo a questão da presença dos aspectos econômicos na análise de fenômenos da cultura pop, evidenciando de forma clara e inquisitória, de que forma imposiçóes econômicas agem sobre a produção de sentido dos produtos. É nesta direção que percebo a necessidade de, a partir de objetos e questôes empíricas específicas, validar a inclinação dos Estudos Culturais para áreas próximas, notadamente a Sociologia da Produção, os Estudos de Consumo e a Economia Política da Comunicação. Em todas estas retrancas teóricas, percebo que se torna fundamental, a arquitetura de arcabouços teóricos a partir da necessidade dos objetos analisáveis.

De forma generalista, faço aqui uma provocação na aproximação que proponho entre abordagens dos Estudos Culturais e da Economia Política da Comunicação no tratamento de análises da cultura pop. Acho fundamental atenuar um ranço excessivamente frankfurtiano que algumas leituras de objetos 
da cultura pop ganham na tradição da Economia Política da Comunicação. Reforço meu interesse por um olhar crítico sobre os fenômenos da Cultura Pop, no entanto, reconheço a necessidade de tratar as indústrias da cultura a partir de releituras menos "apocalípticas", não deixando, com isso, de contemplar, de fato, a carga impositiva que, em alguns casos, as indústrias da cultura exercem sobre seus produtos e instâncias produtivas. Reivindico, portanto, a compreensão de fenômenos da cultura pop em suas complexidades - discursivas e culturológicas - e a ampliação das questôes frankfurtianas de indústria cultural para noçôes mais contemporâneas como indústria(s) cultural(is), indústrias criativas e as novas engrenagens da cultura como produto.

No entanto, acho que o maior legado que a apreensão da cultura pop deve gerar no olhar analítico sobre objetos midiáticos é o reconhecimento de que há "brechas" nas "fórmulas" da mercantilização da cultura. Há "clareiras" das indústrias da cultura. Dessa forma, reconheço que as relaçóes entre instâncias produtivas das indústrias e as dinâmicas de produção se desenham complexas e específicas. No sistema de estúdios do cinema, por exemplo, e na lógica de produção fordista de Hollywood, não se pode lançar um olhar meramente "demonizante" diante das imposiçôes das instituiçôes da indústria. Cabe aqui uma retranca: os estúdios Fox, com sede nos Estados Unidos, que realizam/financiam obras como o blockbuster "X Men" (adaptação da famosa história em quadrinhos e profundamente enraizado na estética do "cinemão-pipoca" de Hollywood) é o mesmo que distribui no mercado mundial as obras mais recentes do cineasta espanhol Pedro Almodóvar ("Fale com Ela", "A Pele que Habito", entre outros). Cabe aqui perceber as "brechas" nas lógicas de produção e consumo: diante de um estágio avançado das lógicas do capitalismo e do marketing, náo sabe pensar o estúdio somente como uma instituição que visa única e deliberadamente o lucro. Sim, o lucro e o retorno financeiro com uma obra são ainda as molas propulsoras da existência das instituiçóes na cultura. No entanto, há, atualmente, disposiçôes do marketing que precisam posicionar estúdios como marcas num mercado global e plural. Com isso, apoiar, distribuir e "assinar embaixo" de filmes "menores", de cinematografias fora do eixo de Hollywood, é uma importante retranca de posicionamento de mercado.

O exemplo da indústria da televisão, no Brasil, talvez, nos ajude a compreender também esta perspectiva. É preciso compreender a Rede Globo não somente como uma empresa de comunicação que produz entretenimento popular - notadamente as telenovelas. O reconhecimento da existência de "brechas" na Rede Globo nos impele a questionar, por exemplo, qual o lugar de um diretor como Luiz Fernando Carvalho dentro da emissora? Ao realizar minisséries como "Os Maias", "Hoje é Dia de Maria" e "Capitu”, temos ciência de que Luiz Fernando Carvalho não está na Globo em função de estabelecer parâmetros de "retorno financeiro". Seus produtos dialogam com a estética do cinema, do teatro, das diversas formas sincréticas de produção cultural. Sua presença na Globo reforça um lugar de experimentalismo que a emissora ainda reserva dentro de sua grade de programaçáo. E o que é o experimentalismo senão uma "brecha" dentro das normas produtivas? Este exemplo nos 
aciona perceber lógicas de distinção no campo da emissoras (assim como pensou Pierre Bourdieu), atreladas a perspectivas de marketing e posicionamento: a Globo se distingue por manter estruturas experimentais, ela se posiciona à parte, ela tem verba para este "plus" em sua programação.

Por outro lado, quero fazer mais uma provocação: por que não fazer análises com inclinaçôes mais estéticas de produtos da cultura pop? Sinto, em alguma medida, que nós, pesquisadores de Comunicação, "driblamos", "fugimos" do clichê. Não é preciso fugir do clichê, pelo contrário. O clichê é uma referência estética posta em prática nos produtos mercantilizados da cultura. Precisamos entender o clichê como parte de uma linhagem que tenta dialogar com o senso comum, com o "gosto médio", com as formas simples de dizer. Neste caso, não se configura em "demérito" a identificação de fórmulas, das lógicas do clichê existentes em produtos da mídia. O clichê é uma chave de entendimento das "engrenagens" discursivas das indústrias da cultura. Se ele é usado, parte-se para a investigação de ordem estético-discursiva. Entendo, portanto, que o clichê é uma forma cultural que é modulável, reconfigurável, portanto, não se trata de uma estrutura estanque e sem mobilidade. Pelo contrário, vivo, o clichê se disfarça sobre camadas de produção de sentido e se revela uma das chaves de entendimento das estéticas da cultura pop. Portanto, de alguma forma, ao "defendermos" o clichê, proponho a releitura de "Sociedade de Espetáculo", de Guy Debord, de maneira menos "apocalíptica” e negativa. Outra provocação: por que atribuímos um tom tão negativo para a noção do simulacro? O simulacro pode não ser uma resposta a um contexto específico?

Sinto necessidade de debater a questão da duração de um artista da cultura pop. Investigar a permanência do artista no contexto midiático é uma questão de performance, assim como pensada por Erving Goffman. Olhem as dicotomias performáticas: vida pública $\mathrm{X}$ vida privada, noção de visibilidade. Estratégias de gestão de imagem. Cabe uma pergunta: o que é "durar" na mídia? Vidas privada e pública, performances musicais em shows, videoclipes, vídeos captados amadoramente e dispostos em plataformas de compartilhamento de conteúdos audiovisuais, fotografias: uma existência documentada. Precisamos reconhecer que estamos diante de novos modelos de star system e da emergência das redes sociais como ambiente performático. Estar pensando diante dessas ferramentas, certamente, nos ajudará a complexificar e aprofundar os estudos sobre fenômenos e produtos da cultura pop. 


\section{Referências Bibliográficas}

AUGÉ, Marc. Não-lugares: Introdução a uma Antropologia da Supermodernidade. São Paulo: Papirus, 1994.

BAUDRILLARD, Jean. Simulaçôes e Simulacros. Lisboa: Relógio D’Água, 1991.

BOURDIEU, Pierre. A Economia das Trocas Simbólicas. São Paulo: Perspectiva, 1974.

CERTEAU, Michel de. Artes de Fazer: A Invenção do Cotidiano. Petrópolis: Vozes, 1994.

CRUZ, Décio Torres. O Pop: Literatura, Mídia e Outras Artes. Salvador: Quarteto, 2003.

DEBORD, Guy. A Sociedade do Espetáculo: Comentários sobre A Sociedade do Espetáculo. São Paulo: Contraponto, 1997.

FEATHERSTONE, Mike. Cultura de Consumo e Pós-Modernismo. São Paulo: Studio Nobel, 1995.

FISKE, John. Understanding Popular Culture. Boston: Unwin Hyman, 1989. . Television Culture. London: Routledge, 1995.

FRITH, Simon. Performing Rites: On the Value of Popular Music. Cambridge/ Massachusetts: Havard University Press, 1996.

GOFFMAN, Erving. A Representação do Eu na Vida Cotidiana. 13.ed. Rio de Janeiro: Vozes, 2006. Comportamento em Lugares Públicos. Rio de Janeiro: Vozes, 2010.

. Ensaios Sobre Rituais de Interação. Rio de Janeiro: Vozes, 2011. 
GOMES, Itânia. O Embaralhamento de fronteiras entre informação e entretenimento e a consideração do jornalismo como processo cultural e histórico. In: CASTRO, Maria Lília Dias e DUARTE, Elizabeth Bastos. Em Torno das Mídias: Práticas e Ambiências. Porto Alegre: Editora Sulina, 2008. p. 96-112.

GOODWIN, Andrew. Dancing in The Distraction Factory: Music Televison and Popular Culture. Minneapolis: University of Minnesota Press, 1992.

HAUG, Wolfgng Fritz. Crítica da Estética da Mercadoria. São Paulo: Unesp, 1997.

HERSCHMANN, Micael. Lapa, Cidade da Música. Rio de Janeiro: Maud X, 2007.

HERSCHMANN, Micael e KISCHINHEVSKY, Marcelo. A "Geração Podcasting" e os Novos Usos do Rádio na Sociedade do Espetáculo e do Entretenimento. In: XVI Encontro da da Associação Nacional de Programas de Pós-Graduação em Comunicação (Compós). Anais Eletrônicos. Curitiba (PR), 2007. Disponível em: http://www.compos.org.br/data/biblioteca_263.pdf. Acesso em 10 de maio de 2012.

JANOTTI, Jeder. Entretenimento, Produtos Midiáticos e Fruição Estética. In: XVIII Encontro da Associação Nacional de Programas de Pós-Graduação em Comunicação (Compós). Anais Eletrônicos. Belo Horizonte (MG), 2009. Disponível em: http://www.compos.org. br/data/biblioteca_1150.pdf. Acesso em 12 de maio de 2012.

KELLNER, Douglas. Cultura da Mídia. Bauru (SP): Editora da Universidade do Sagrado Coração (Edusc), 2001.

LEMOS, André. Mídias Locativas e Territórios Informacionais. Salvador, 2008. Disponível em http://www.facom.ufba.br/ciberpesquisa/andrelemos/midia_locativa.pdf. Acesso em 12 de maio de 2012.

LIPPARD, Lucy. Pop Art. London: Thames and Hudson, 1998. 
MICKEY, J.T. A Postmodern View of Public Relations: Sign and Reality. In: Public Relations Review. New York: NYU Press, 1997. p. 271-284.

MIDDLETON, Richard. Studying Popular Music. San Francisco: Open University Press, 1991.

SEVCENKO, Nicolau. A Indústria do Entretenimento e a Sociedade de Espetáculos. In: A Corrida para o Século XXI. 7. reimp. São Paulo: Companhia das Letras, 2005. p. 73-94.

SHUKER, Roy. Understanding Popular Music. New York: Routledge, 1994.

Vocabulário de Música Pop. São Paulo: Hedra, 1999.

\section{Notas}

(1) Trabalho apresentado no GP Comunicação, Música e Entretenimento do XIII Encontro dos Grupos de Pesquisa em Comunicação, evento componente do XXXVI Congresso Brasileiro de Ciências da Comunicação, na cidade de Manaus (AM).

(2) Desde então, instituí o Grupo de Pesquisa em Mídia, Entretenimento e Cultura Pop (Grupop), no Programa de Pós-Graduação em Comunicaçáo (PPGC) da Universidade Federal da Paraíba (UFPB), onde desenvolvo o projeto de pesquisa "Cultura Pop: Performances, Produtos e Territorialidades".

(3) A defesa do popular traduz uma atitude artística adversa ao hermetismo da arte moderna. Nesse sentido, a "Pop Art" operava com signos estéticos de cores massificados pela publicidade e pelo consumo, usando tinta acrílica, poliéster, látex, produtos com cores intensas, fluorescentes, brilhantes e vibrantes, reproduzindo objetos do cotidiano em tamanho consideravelmente grande fazendo referência a uma estética da sociedade de consumo. (LIPPARD, 1998, p. 16) 